\title{
Presença de familiares durante a indução anestésica de crianças: Revisão da literatura
}

\author{
Presence of family members during induction of anesthesia in children: A literature review \\ La presencia de los familiares durante la inducción anestésica en los niños: Revisión de la \\ literatura
}

Silvana Menezes ${ }^{1}$, Lilian D’Angelo Tomazinho

\begin{abstract}
RESUMO: Na indução anestésica a criança pode ficar agitada, aumentando o risco de apneia e de laringoespasmo. A presença do pai/ mãe pode diminuir a ansiedade e melhorar a cooperação. Objetivo: Identificar, na literatura, os aspectos positivos e negativos que a experiência em presenciar a indução anestésica de crianças pode conferir aos familiares, à própria criança e aos profissionais de centro cirúrgico. Método: Revisão de literatura, na qual foram utilizados artigos científicos publicados de 1989 a 2012, indexados nas bases de dados National Library of Medicine (MEDLINE) e Literatura Latino-Americana e do Caribe em Ciências da Saúde (LILACS), com os descritores 'pais and criança and centros de cirurgia'. Resultados: As experiências de permitir a entrada dos pais na sala de indução anestésica mostram que ocorre uma redução da ansiedade das crianças e dos pais, e menor necessidade de restrição física. Com relação aos profissionais, existe uma melhor relação enfermeiro-paciente, embora alguns profissionais apresentem ansiedade com relação ao seu desempenho, além de inconvenientes relacionados a recursos humanos necessários para a implantação desta prática. Considerações Finais: Em virtude dos benefícios decorrentes da adoção dessa prática, este trabalho mostra a importância de viabilizar, cada vez mais, a presença dos pais durante a indução anestésica de crianças.
\end{abstract}

PAlaVRAS-CHAVE: Pais. Criança. Centros de Cirurgia.

ABSTRACT: Children usually become anxious and agitated during anesthetic induction, increasing the risk of apnea and laryngospasm. The presence of a family member can decrease anxiety and improve cooperation, reducing risks. Objective: To identify, in the literature, positive and negative aspects that the experience to witnessing anesthetic induction in children can provide to family members, the children themselves, and the surgical center staff. Method: A literature review using the keywords "parents", "child", and "surgicenters" on scientific articles published between 1989 and 2012 indexed at National Library of Medicine (MEDLINE) and Latin American and Caribbean Health Sciences (LILACS) database. Results: The experiences of allowing the presence of parents in the anesthetic induction room show that there is a reduction of the anxiety level of children and parents, with lower necessity for physical restraint. Regarding the surgical center staff, despite the anxiety presented by professionals in relation to their performance and the difficulties related to the human resources needed to implement this practice, a better nurse-patient relationship was observed. Conclusions: In view of the benefits arising from the adoption of this practice, this work shows the importance of increasingly enabling parental presence during induction of anesthesia in children.

KEYWORDS: Parents. Child. Surgicenters.

RESUMEN: En la inducción anestésica, el niño puede quedarse ansioso y agitado, aumentando el riesgo de apnea y de laringoespasmo. La presencia del padre/madre puede disminuir la ansiedad y mejorar la cooperación, reduciendo así los riesgos. Objetivo: Identificar en la literatura los aspectos positivos y negativos que el hecho de presenciar la inducción anestésica en los niños puede proporcionar a los familiares, al propio niño y a los profesionales del quirófano. Metodología: Este estudio es una revisión de la literatura, en el que se utilizaron artículos científicos publicados de 1989 a 2012, indexados en las bases de datos Biblioteca Nacional de Medicina (MEDLINE) y Literatura Latino-Americana y del Caribe en Ciencias de la Salud (LILACS) con las palabras clave "padres and niño and quirófanos". Resultados: La experiencia de dejar entrar a los padres en la sala de inducción anestésica demuestra que se verifica una reducción de la ansiedad en niños y padres, y una menor necesidad de restricción física. Con relación a los profesionales, hay una mejor relación enfermero-paciente, aunque algunos profesionales muestren ansiedad a la hora de su desempeño, junto con inconvenientes relacionados a los recursos humanos necesarios para la aplicación de esta práctica. Conclusión: En virtud de los beneficios derivados de la adopción de esta práctica, este trabajo muestra la importancia de viabilizar, cada vez más, la presencia de los padres durante la inducción anestésica en los niños.

PALABRAS ClAVE: Padres. Niño. Quirófanos.

${ }^{1}$ Enfermeira. Especialista em Emergência e em Centro Cirúrgico. Enfermeira Assistencial Sênior do Bloco Operatório do Hospital Sírio Libanês. Rua Ataulfo Alves, 624.

Vila Industrial. CEP 03251-190. São Paulo, SP, Brasil.

Telefones: 2704-7387 (residencial), 981286648 (celular), 3155-0385 (comercial). E-mail: silvana.menezes@hsl.org.br

${ }^{2}$ Enfermeira. Especialista em Centro Cirúrgico. Enfermeira Assistencial Pleno do Bloco Operatório do Hospital Sírio Libanês. Rua Domélia, 84. Apto. 32. Tucuruvi.

CEP 02308-100. São Paulo, SP, Brasil.

Telefones: 2204-3971 (residencial), 99944-0820 (celular), 3155-0385 (comercial). E-mail: lilian.tomazinho@hsl.org.br. 


\section{Introdução}

Para a criança, a separação dos pais à porta do Centro Cirúrgico pode ser um procedimento desconfortante, assim como a indução anestésica e o pós-operatório imediato ${ }^{1}$.

$\mathrm{Na}$ indução anestésica, quando a criança está ansiosa, ela pode ficar agitada, o que está associado ao aumento de apneia e do risco de laringoespasmo. A presença de um dos pais é fundamental para diminuir esta ansiedade e melhorar a cooperação ${ }^{2,3}$.

A literatura sobre a hospitalização infantil caminha na direção da humanização, sendo que, até 1980, os artigos abordavam somente os efeitos da hospitalização. Após este período, os textos passaram a mencionar os benefícios da participação dos pais como acompanhante ${ }^{1}$.

Esta mudança de foco, além de obedecer ao Estatuto da Criança e do Adolescente, Lei 8.069 de 13 de julho de 1990, cujo artigo 12 menciona que "os estabelecimentos de saúde devem proporcionar condições de permanência em tempo integral de um dos pais ou responsável, nos casos de internação de crianças e adolescentes", também ocorreu em virtude da percepção de que a presença dos pais durante a indução anestésica diminui a ansiedade das crianças e melhora a cooperação ${ }^{3}$.

Acredita-se que, entre os profissionais de saúde, no Brasil, esta seja uma questão que traz certa resistência para a aceitação e a possível permissão da presença dos pais de crianças na sala de cirurgia durante a indução anestésica devido aos valores que ainda se cultivam na área da saúde, que exclui a participação de membros da família em algumas situações dentro das instituições hospitalares. Ainda assim, introduzir esta prática no Brasil envolveria conhecer melhor os aspectos de crença e valores das famílias envolvidas, e o grau de entendimento destas sobre o acontecimento.

Diante desta realidade, acredita-se ser necessário conhecer como este tema tem sido abordado em outros países do mundo, analisando-se os aspectos positivos e negativos considerados pelos profissionais, assim como os aspectos considerados pelos familiares, com a finalidade de subsidiar o desenvolvimento desta prática e planejar estratégias que possibilitem a implementação dessa ação de humanização nos nossos serviços de cirurgia.

\section{Objetivo}

Identificar, na literatura, os aspectos positivos e negativos que a experiência em presenciar a indução anestésica de crianças pode conferir aos familiares, à própria criança e aos profissionais de centro cirúrgico.

\section{Método}

Este estudo é uma revisão da literatura, realizada por meio do levantamento de artigos científicos indexados nas bases de dados National Library of Medicine (MEDLINE), utilizando-se os descritores 'parents and child and surgicenters', e Literatura Latino-Americana e do Caribe em Ciências da Saúde (LILACS), com os descritores 'pais and criança and centros de cirurgia'.

Foram estabelecidos, como critérios de inclusão, artigos publicados de 1989 a 2012, de qualquer país, nos idiomas inglês, espanhol ou português. Após a identificação dos artigos, foi realizada a leitura crítica de cada um deles, para identificar os aspectos mais relevantes, considerando-se o objetivo deste estudo. Os resultados foram agrupados e apresentados de forma descritiva em quadros e tabelas.

\section{Resultados e discussão}

Foram identificados 103 artigos inicialmente e, destes, foram excluídos os artigos que abordavam a presença dos pais em outro local que não o centro cirúrgico e a sala de indução anestésica. Treze artigos foram selecionados para a revisão e, destes, 12 apresentaram relevância para a análise por responder aos critérios de inclusão.

Os artigos selecionados para fazer parte da amostra deste estudo estão listados no Quadro 1, que relaciona os achados positivos e negativos descritos, e que constam na lista de referências.

Trata-se de dois artigos nacionais e dez internacionais. Dentre as publicações selecionadas, dois são estudos randomizados controlados, dois são estudos observacionais, dois são descrições de programas implementados, dois são estudos exploratórios descritivos, um estudo prospectivo, um estudo de casos controlados, uma pesquisa transversal de campo e um relato de opinião.

A análise dos artigos permitiu a identificação dos principais pontos positivos e negativos citados nos textos publicados. Eles estão evidenciados nas Tabelas 1 e 2 .

As reações de pais e crianças durante a indução anestésica presenciada têm sido associadas ao aumento de satisfação dos pais em relação ao funcionamento global do hospital ${ }^{6-9}$. Muitos deles preferem estar com a criança na indução anestésica $^{10}$.

O Quadro 2 retrata que, em 50\% (seis) dos textos analisados, os autores identificaram a redução do estresse, da ansiedade e da agitação da criança, e ainda que os pais estavam menos ansiosos quando acompanhavam seus filhos durante a indução da anestesia.

Em 33\% (quatro) dos artigos, foi citado que a indução da criança foi mais suave com a presença dos pais.

Assim, as experiências de permitir a entrada dos pais na sala de indução anestésica mostram que ocorre uma redução efetiva da ansiedade das crianças e dos pais ${ }^{4,5}$, e ainda menor necessidade de restrição física ${ }^{6}$.

A melhor relação enfermeiro-paciente ${ }^{5}$ foi mencionada em somente um artigo e, nesse caso, foi feita por um dos pais que participaram do programa de orientação cirúrgica para crianças e pais num hospital pediátrico. 
Quadro 1. Descrição dos aspectos positivos e negativos encontrados na literatura sobre a presença de membros da família durante a indução anestésica de crianças. São Paulo, 2014.

\begin{tabular}{|c|c|c|c|c|c|}
\hline AUTOR/ANO & PAÍS & $\begin{array}{l}\text { TIPO DE } \\
\text { ESTUDO }\end{array}$ & $\begin{array}{l}\text { MATERIAL/ } \\
\text { CASUÍSTICA }\end{array}$ & ASPECTOS POSITIVOS & ASPECTOS NEGATIVOS \\
\hline $\begin{array}{l}\text { Garcia MA et al. } \\
(2001)^{1}\end{array}$ & Brasil & $\begin{array}{l}\text { Pesquisa } \\
\text { transversal de } \\
\text { campo }\end{array}$ & $\begin{array}{l}\text { Foi utilizado um } \\
\text { questionário aplicado para } \\
\text { a Equipe de Enfermagem } \\
\text { para conhecer a percepção } \\
\text { desta a respeito da utilização } \\
\text { de estratégias lúdicas } \\
\text { para crianças na recepção } \\
\text { da Unidade de Centro } \\
\text { Cirúrgico. }\end{array}$ & $\begin{array}{l}\text { A maioria dos participantes } \\
\text { considerou que as } \\
\text { estratégias lúdicas diminuem } \\
\text { o estresse da criança e da } \\
\text { mãe na entrada do CC. }\end{array}$ & $\begin{array}{l}\text { O estresse é diminuído } \\
\text { somente na porta do CC, mas } \\
\text { não após a entrada na sala de } \\
\text { operações. }\end{array}$ \\
\hline $\begin{array}{l}\text { Krowchuk HV, } \\
\text { Rieker, M }(2007)^{2}\end{array}$ & $\begin{array}{l}\text { Estados } \\
\text { Unidos }\end{array}$ & Opinião & $\begin{array}{l}\text { Opinião de especialistas } \\
\text { sobre os prós e os contras } \\
\text { da presença dos pais durante } \\
\text { a indução anestésica de } \\
\text { crianças. }\end{array}$ & $\begin{array}{l}\text { Os pais podem oferecer } \\
\text { conforto para a criança } \\
\text { no momento da indução } \\
\text { anestésica e diminuir a } \\
\text { agitação que está associada } \\
\text { ao risco de laringoespasmo. }\end{array}$ & $\begin{array}{l}\text { Acreditam que alguns } \\
\text { profissionais podem ficar } \\
\text { muito ansiosos sobre o } \\
\text { seu desempenho quando } \\
\text { sentem que os pais estão } \\
\text { observando. Pode haver } \\
\text { inconvenientes de se } \\
\text { implementar o programa da } \\
\text { presença dos pais no Centro } \\
\text { Cirúrgico pela necessidade } \\
\text { da equipe e de recursos } \\
\text { para dar suporte a esses } \\
\text { acompanhantes. }\end{array}$ \\
\hline $\begin{array}{l}\text { Jukemura MFM, } \\
\text { Peniche ACG } \\
(2012)^{3}\end{array}$ & Brasil & $\begin{array}{l}\text { Estudo } \\
\text { exploratório } \\
\text { descritivo }\end{array}$ & $\begin{array}{l}\text { Foram realizadas entrevistas } \\
\text { na unidade de recuperação } \\
\text { pós-anestésica com } \\
\text { acompanhantes de crianças } \\
\text { que foram submetidas a } \\
\text { procedimentos cirúrgicos } \\
\text { eletivos ou de urgência. }\end{array}$ & $\begin{array}{l}\text { A presença dos pais durante } \\
\text { a indução anestésica diminui } \\
\text { a ansiedade das crianças } \\
\text { e melhora a cooperação. } \\
\text { Os pais se sentem seguros, } \\
\text { tranquilos e relatam } \\
\text { satisfação em estar ao lado } \\
\text { da criança. }\end{array}$ & $\begin{array}{l}\text { Identificada necessidade de } \\
\text { orientação pré-operatória à } \\
\text { criança e ao seu familiar. }\end{array}$ \\
\hline $\begin{array}{l}\text { Gauderer } \\
\text { MWL et al. } \\
(1989)^{4}\end{array}$ & $\begin{array}{l}\text { Estados } \\
\text { Unidos }\end{array}$ & $\begin{array}{l}\text { Estudo } \\
\text { de casos } \\
\text { controlados }\end{array}$ & $\begin{array}{l}\text { Realizado acompanhamento } \\
\text { observacional de } 3086 \\
\text { crianças operadas no } \\
\text { período de quatro anos. }\end{array}$ & $\begin{array}{l}\text { Redução efetiva da } \\
\text { ansiedade das crianças e dos } \\
\text { pais, e indução mais suave. }\end{array}$ & $\begin{array}{l}\text { Pode haver: ruptura na } \\
\text { organização da rotina } \\
\text { da sala de operações, } \\
\text { imprevisibilidade sobre o } \\
\text { comportamento dos pais e } \\
\text { aumento dos custos e do } \\
\text { tempo. }\end{array}$ \\
\hline $\begin{array}{l}\text { Adams HA } \\
(2011)^{5}\end{array}$ & $\begin{array}{l}\text { Estados } \\
\text { Unidos }\end{array}$ & $\begin{array}{l}\text { Descrição de } \\
\text { um programa } \\
\text { de atendimento } \\
\text { pediátrico em } \\
\text { um centro } \\
\text { cirúrgico }\end{array}$ & $\begin{array}{l}\text { Descreve como foi } \\
\text { implementado o programa } \\
\text { de orientação cirúrgica para } \\
\text { crianças e pais num hospital } \\
\text { pediátrico em Billings, } \\
\text { Montana, Estados Unidos. }\end{array}$ & $\begin{array}{l}\text { Durante uma visita } \\
\text { programada, pais e crianças } \\
\text { conhecem o ambiente do } \\
\text { Centro Cirúrgico e recebem } \\
\text { informações exatas do } \\
\text { que acontecerá no dia } \\
\text { da cirurgia, incluindo a } \\
\text { apresentação dos materiais } \\
\text { para monitorização, sedação } \\
\text { e o uniforme privativo. Na } \\
\text { opinião dos pais, há redução } \\
\text { da ansiedade e melhor } \\
\text { relação enfermeiro-paciente. }\end{array}$ & Não descrito. \\
\hline
\end{tabular}


Quadro 1. Continuação...

\begin{tabular}{|c|c|c|c|c|c|}
\hline AUTOR/ANO & PAÍS & $\begin{array}{l}\text { TIPO DE } \\
\text { ESTUDO }\end{array}$ & $\begin{array}{l}\text { MATERIAL/ } \\
\text { CASUÍSTICA }\end{array}$ & ASPECTOS POSITIVOS & ASPECTOS NEGATIVOS \\
\hline $\begin{array}{l}\text { Soliveres J et al. } \\
(2011)^{6}\end{array}$ & Espanha & $\begin{array}{l}\text { Estudo } \\
\text { observacional } \\
\text { controlado }\end{array}$ & $\begin{array}{l}\text { Estudo com dois grupos, } \\
\text { incluindo } 40 \text { crianças } \\
\text { ASA-1 de cirurgias } \\
\text { eletivas aleatoriamente } \\
\text { escolhidas para um dos } \\
\text { grupos. Em um grupo, os } \\
\text { pais acompanhavam as } \\
\text { crianças na sala de cirurgia } \\
\text { durante a indução anestésica } \\
\text { e, no outro grupo, não } \\
\text { acompanhavam. }\end{array}$ & $\begin{array}{l}\text { Indução anestésica } \\
\text { mais suave no grupo } \\
\text { acompanhado dos pais, } \\
\text { com menor necessidade } \\
\text { de restrição física e mais } \\
\text { qualidade no pós-operatório. }\end{array}$ & $\begin{array}{l}\text { Há pouca pesquisa nesta área } \\
\text { e os resultados podem não } \\
\text { ser conclusivos. }\end{array}$ \\
\hline $\begin{array}{l}\text { LaRosa-Nash } \\
\text { PA et al. }(1995)^{7}\end{array}$ & $\begin{array}{l}\text { Estados } \\
\text { Unidos }\end{array}$ & $\begin{array}{l}\text { Descrição de } \\
\text { um programa } \\
\text { PPI (parent- } \\
\text { present } \\
\text { induction) }\end{array}$ & $\begin{array}{l}\text { Descreve como foi } \\
\text { implementado o programa } \\
\text { de presença dos pais na } \\
\text { indução anestésica num } \\
\text { hospital pediátrico em } \\
\text { Boston, Estados Unidos. }\end{array}$ & $\begin{array}{l}\text { Crianças acompanhadas } \\
\text { dos pais durante a indução } \\
\text { anestésica ficam mais } \\
\text { relaxadas e diminui-se o } \\
\text { medo. A pré-medicação, em } \\
\text { geral, não é necessária. }\end{array}$ & $\begin{array}{l}\text { Os pais devem ser orientados } \\
\text { em relação a toda situação } \\
\text { para que possa ajudar na } \\
\text { diminuição da ansiedade dos } \\
\text { filhos, criando um programa } \\
\text { de educação, no qual a } \\
\text { equipe multidisciplinar } \\
\text { explica os procedimentos e } \\
\text { esclarece dúvidas. }\end{array}$ \\
\hline $\begin{array}{l}\text { Kain ZN et al. } \\
(2003)^{9}\end{array}$ & $\begin{array}{l}\text { Estados } \\
\text { Unidos }\end{array}$ & $\begin{array}{l}\text { Estudo } \\
\text { randomizado } \\
\text { controlado }\end{array}$ & $\begin{array}{l}\text { Um grupo de pais } \\
\text { acompanhou os filhos } \\
\text { durante a indução anestésica } \\
\text { no Centro Cirúrgico e } \\
\text { outro grupo foi separado } \\
\text { dos filhos na entrada do } \\
\text { Centro Cirúrgico. Os grupos } \\
\text { foram avaliados por meio } \\
\text { de escalas de ansiedade. Os } \\
\text { pais tiveram a frequência } \\
\text { cardíaca e a pressão arterial } \\
\text { monitoradas. }\end{array}$ & $\begin{array}{l}\text { Não houve diferença nos } \\
\text { valores de pressão arterial } \\
\text { em nenhum grupo. Depois } \\
\text { da separação, os pais } \\
\text { que acompanharam os } \\
\text { filhos durante a indução } \\
\text { apresentaram frequência } \\
\text { cardíaca menor do que os } \\
\text { pais que foram separados } \\
\text { dos filhos na entrada } \\
\text { do Centro Cirúrgico. } \\
\text { A presença dos pais na } \\
\text { indução anestésica tem } \\
\text { sido associada ao aumento } \\
\text { de satisfação dos pais em } \\
\text { relação ao funcionamento } \\
\text { global do hospital. }\end{array}$ & $\begin{array}{l}\text { Houve aumento da } \\
\text { frequência cardíaca dos pais } \\
\text { presentes durante a indução } \\
\text { anestésica dos filhos na sala } \\
\text { de operação. }\end{array}$ \\
\hline $\begin{array}{l}\text { Braude N et al. } \\
(1990)^{10}\end{array}$ & Inglaterra & $\begin{array}{l}\text { Estudo } \\
\text { prospectivo }\end{array}$ & $\begin{array}{l}\text { Entrevistaram pais que } \\
\text { estiveram presentes nas } \\
\text { induções anestésicas de seus } \\
\text { filhos. }\end{array}$ & $\begin{array}{l}\text { Dos } 117 \text { pais entrevistados, } \\
32 \% \text { disseram preferir estar } \\
\text { com a criança na indução } \\
\text { anestésica. }\end{array}$ & $\begin{array}{l}18 \% \text { gostariam de não estar } \\
\text { presentes neste momento. }\end{array}$ \\
\hline $\begin{array}{l}\text { Berghmans J et al. } \\
(2012)^{11}\end{array}$ & Bélgica & $\begin{array}{l}\text { Estudo } \\
\text { randomizado } \\
\text { controlado }\end{array}$ & $\begin{array}{l}\text { Mensurada a ansiedade de } \\
120 \text { pais cujos filhos seriam } \\
\text { submetidos à cirurgia. Um } \\
\text { grupo recebia orientações } \\
\text { a partir de vídeos e } \\
\text { discussões. }\end{array}$ & $\begin{array}{l}\text { Encontraram pais muito } \\
\text { motivados a acompanhar } \\
\text { os filhos durante a indução } \\
\text { anestésica. }\end{array}$ & $\begin{array}{l}\text { A ansiedade do pai ou da } \\
\text { mãe que está acompanhando } \\
\text { a criança pode aumentar. }\end{array}$ \\
\hline $\begin{array}{l}\text { Himes MK et al. } \\
(2003)^{12}\end{array}$ & $\begin{array}{l}\text { Estados } \\
\text { Unidos }\end{array}$ & $\begin{array}{l}\text { Estudo } \\
\text { exploratório } \\
\text { descritivo }\end{array}$ & $\begin{array}{l}\text { Foram entregues } \\
\text { questionários aos pais que } \\
\text { estiveram presentes na sala } \\
\text { de indução anestésica com } \\
\text { seus filhos para conhecer } \\
\text { sobre o preparo destes } \\
\text { sobre a indução e quais as } \\
\text { experiências vividas nesse } \\
\text { período. }\end{array}$ & $\begin{array}{l}\text { Com o preparo adequado, } \\
\text { os pais podem participar } \\
\text { da indução anestésica de } \\
\text { maneira mais benéfica. }\end{array}$ & $\begin{array}{l}\text { Pais ansiosos podem } \\
\text { aumentar a ansiedade da } \\
\text { criança e do Anestesista } \\
\text { no Centro Cirúrgico. } \\
\text { Alguns pais citaram que } \\
\text { poderiam ter sido mais bem } \\
\text { preparados. }\end{array}$ \\
\hline
\end{tabular}


Quadro 1. Continuação...

\begin{tabular}{|l|l|l|l|l|l|}
\hline AUTOR/ANO & PAÍS & \multicolumn{1}{|c|}{$\begin{array}{c}\text { TIPO DE } \\
\text { ESTUDO }\end{array}$} & \multicolumn{1}{|c|}{$\begin{array}{c}\text { MATERIAL/ } \\
\text { CASUÍSTICA }\end{array}$} & ASPECTOS POSITIVOS & ASPECTOS NEGATIVOS \\
\hline $\begin{array}{l}\text { Chorney JM et al. } \\
(2009)^{13}\end{array}$ & $\begin{array}{l}\text { Estados } \\
\text { Unidos }\end{array}$ & $\begin{array}{l}\text { Estudo } \\
\text { observacional }\end{array}$ & $\begin{array}{l}\text { Utilizaram uma escala para } \\
\text { analisar o comportamento } \\
\text { dos pais, crianças e } \\
\text { profissionais durante a } \\
\text { indução anestésica. }\end{array}$ & $\begin{array}{l}\text { Os profissionais de saúde } \\
\text { podem direcionar o } \\
\text { comportamento que desejam } \\
\text { dos pais durante a indução } \\
\text { anestésica presenciada. }\end{array}$ & $\begin{array}{l}\text { O treinamento de cada } \\
\text { familiar que estará presente } \\
\text { na indução anestésica é um } \\
\text { processo demorado. }\end{array}$ \\
\hline
\end{tabular}

Tabela 1. Principais pontos positivos mencionados nos artigos analisados.

\begin{tabular}{|c|c|c|}
\hline Aspecto mencionado & Quantidade de Artigos & Valor (\%) \\
\hline Redução do estresse, da ansiedade e da agitação da criança & 6 & 50 \\
\hline Pais menos ansiosos, mais tranquilos e satisfeitos & 6 & 50 \\
\hline Indução anestésica da criança mais suave, menor necessidade de restrição física & 4 & 33 \\
\hline Melhor relação enfermeiro-paciente & 1 & 8 \\
\hline
\end{tabular}

Tabela 2. Principais pontos negativos mencionados nos artigos analisados.

\begin{tabular}{|c|c|c|}
\hline Aspecto mencionado & Quantidade de Artigos & Valor $(\%)$ \\
\hline Necessidade de pré-orientação para os pais & 4 & 33 \\
\hline $\begin{array}{l}\text { Aumento da ansiedade e da frequência cardíaca dos pais, e imprevisibilidade do } \\
\text { comportamento }\end{array}$ & 3 & 25 \\
\hline Aumento do tempo, custo, necessidade de recursos, ruptura da rotina & 3 & 25 \\
\hline Profissionais ansiosos & 2 & 16 \\
\hline Possível aumento da ansiedade da criança pelos pais ansiosos presentes & 1 & 8 \\
\hline
\end{tabular}

Quadro 2. Principais pontos positivos mencionados nos artigos analisados.

\begin{tabular}{|l|c|}
\hline \multicolumn{1}{|c|}{ Aspecto mencionado } & Quantidade de Artigos \\
\hline Redução do estresse, da ansiedade e da agitação da criança & 6 \\
\hline Pais menos ansiosos, mais tranquilos e satisfeitos & 6 \\
\hline Indução anestésica da criança mais suave, menor necessidade de restrição física & 4 \\
\hline Melhor relação enfermeiro-paciente & 1 \\
\hline
\end{tabular}

Somente um artigo traz a menção de profissionais sobre o benefício de estratégias lúdicas para diminuir o estresse da criança e da mãe na entrada do Centro Cirúrgico ${ }^{1}$, mas, nesse trabalho, os pais não acompanhavam os filhos durante a indução. Esse artigo, apesar de restringir a análise para o objetivo do presente trabalho, foi incluído na amostra justamente porque expõe que as crianças apresentavam aumento do estresse quando separadas dos pais à porta do Centro Cirúrgico. Observe-se que ocorreu tal aumento do estresse mesmo tendo sido usadas estratégias lúdicas pelos profissionais de saúde na recepção dessas crianças na unidade de cirurgia, fato este que reflete muito a realidade observada na vivência diária na recepção de crianças nos Centros Cirúrgicos.

Tais observações fazem crer que os profissionais de saúde podem estar pouco preparados para participar de programas que implementem a presença dos pais durante a indução anestésica de crianças ou que há a necessidade de mais trabalhos que abordem a opinião dos profissionais sobre este assunto.

Pelos aspectos positivos analisados, parece ser pertinente insistir no benefício da presença paterna durante a indução anestésica $^{6}$.

O Quadro 3 demonstra os principais pontos negativos mencionados nos artigos. Percebe-se que a necessidade de pré-orientação para os pais é um dos aspectos considerados de maior relevância, citado em 33\% (quatro) dos textos.

Os autores discutiram estratégias para o ensino de pais de crianças que seriam submetidas a procedimentos anestésicocirúrgicos, enfatizando essa necessidade (5, $, 11,12$.

Garcia et al. ${ }^{1}$ relataram a importância de orientar os pais sobre a separação dos filhos encaminhados ao Centro 
Quadro 3. Principais pontos negativos mencionados nos artigos analisados. São Paulo, 2014.

\begin{tabular}{|c|c|}
\hline Aspecto mencionado & Quantidade de Artigos \\
\hline Necessidade de pré-orientação para os pais & 4 \\
\hline Aumento da ansiedade e da frequência cardíaca dos pais, e imprevisibilidade do comportamento & 3 \\
\hline Aumento do tempo, custo, necessidade de recursos, ruptura da rotina & 3 \\
\hline Profissionais ansiosos & 2 \\
\hline
\end{tabular}

Cirúrgico e que a utilização de estratégias diminui o estresse da mãe e da criança somente na porta do Centro Cirúrgico, mas não após a entrada na sala de operações. Afirmam que os sentimentos de medo e ansiedade podem ser minimizados com a permissão da permanência dos pais ao lado da criança.

Adams ${ }^{5}$ publicou artigo sobre um programa de educação para pacientes pediátricos e seus pais, realizado no Yellowstone Surgery Center, em Billings, Montana. O programa inclui visita antecipada ao Centro Cirúrgico para crianças com cirurgias eletivas. Relatam que, especialmente para pré-escolares, essa visita cria familiaridade com o ambiente, diminuindo a ansiedade para o dia da cirurgia. $\mathrm{Na}$ visita, os pais e as crianças conhecem o ambiente do Centro Cirúrgico e recebem informações exatas do que acontecerá no dia da cirurgia, incluindo a apresentação dos materiais para monitorização e sedação, e o uniforme privativo. $\mathrm{O}$ programa continua por, aproximadamente, uma semana após a cirurgia. A criança e os pais recebem um cartão postal de congratulações e respondem a uma pesquisa sobre a experiência de participar do programa. Os benefícios descritos após um ano da implementação do programa são: redução da ansiedade dos pais e crianças, e melhor relação enfermeiro-paciente.

Himes et al. ${ }^{12}$ afirmaram que pais ansiosos podem aumentar a ansiedade da criança e do Anestesista no Centro Cirúrgico. Alguns pais citaram que poderiam ter sido mais bem preparados. O resultado desse estudo mostra que, com o preparo adequado, os pais podem participar da indução anestésica de maneira mais benéfica.

Entretanto, pode haver inconvenientes de se implementar o programa da presença dos pais no Centro Cirúrgico relacionados à necessidade de recursos humanos para dar suporte aos familiares ${ }^{2}$.

Considerando-se que a necessidade de pré-orientação aos pais possa ser um requisito para a presença desses familiares durante a indução anestésica e que o treinamento de cada familiar, que estará presente na indução anestésica, é um processo demorado e que pode gerar custos, entende-se que esse é um aspecto negativo para a implementação do programa, conforme mencionado em $25 \%$ (três) dos artigos.

O modelo atual de gestão da saúde impede - ou dificulta - que a abordagem dos pais e crianças seja feita de maneira antecipada pela Enfermeira do Centro Cirúrgico. Ainda assim, há resultados que sugerem que os profissionais de saúde podem direcionar o comportamento que desejam dos pais ${ }^{13}$.

Corroborando com esses achados, a experiência diária permite afirmar que é possível que, mesmo sem o preparo antecipado dos pais, já dentro da sala de operações, um profissional pode garantir que o familiar mantenha-se tranquilo e seguro, transmitindo esses sentimentos à criança antes da indução anestésica. Cabe também a esse profissional ter a percepção do momento adequado de conduzir o familiar para a recepção, deixando a sala de cirurgia, após a indução da anestesia.

Quanto aos profissionais de assistência, 16\% (dois) dos artigos mencionam que alguns podem ficar muito ansiosos sobre o seu desempenho quando sentem que os pais estão observando. Portanto, considera-se esse aspecto como negativo, uma vez que não se desejam mudanças no comportamento dos profissionais diante dos acompanhantes na indução anestésica de crianças, mas, pelo contrário, espera-se que os profissionais possam dar suporte adequado também aos pais presentes.

\section{Considerações finais}

A partir de 1976, os pais foram encorajados a estar presentes durante cesarianas e, em 1984, o conceito de pais presentes na sala operatória foi introduzido na área médica ${ }^{4}$.

A maioria dos textos ressalta as vantagens da presença da família ou de pessoa muito próxima da criança durante a indução anestésica. Assim, os relatos mostram que é possível adequar os processos no Centro Cirúrgico, estruturando suas equipes e criando discussões construtivas entre os membros da equipe multiprofissional do serviço. Deve-se, também, abordar de maneira clara as famílias destes pacientes, deixando livre a escolha de acompanhar ou não a criança durante a indução da anestesia.

Observou-se que, em muitos países, esta situação apresenta maior aceitação pelas equipes de saúde e pelos familiares. No Brasil, a prática diária tem mostrado a resistência da permissão hospitalar com maior frequência.

Em virtude dos benefícios decorrentes da adoção dessa prática, este trabalho demonstra a importância de viabilizar, cada vez mais, a presença dos pais durante a indução anestésica de crianças. 


\section{Referências}

1. Garcia MA, Fernandes TR, Braga EM, Caldeira SM. Estratégias lúdicas para a recepção de crianças em centro cirúrgico. Rev. SOBECC. 2001;16(1):48-55.

2. Krowchuk HV, Rieker M. Pro: should parents be present during their child's anesthesia induction? MCN Am J. Matern. Child. Nurs. 2007;32(2):72-3. PMid:17356409. http://dx.doi. org/10.1097/01.NMC.0000264283.18856.2f

3. Jukemura MFM, Peniche ACG. Necessidades do acompanhante da criança em unidade de recuperação anestésica. Rev. SOBECC. 2012;15(3):25-32.

4. Gauderer MWL, Lorig JL, Eastwood DW. Is there a place for parents in the operating room? J Pediatr Surg. 1989;24(7):705-7. http://dx.doi.org/10.1016/S0022-3468(89)80726-2

5. Adams HA. A perioperative education program for pediatric pacientes and their parents. AORN J. 2011;93(4):472-81. PMid:21459185. http://dx.doi.org/10.1016/j.aorn.2010.11.030

6. Soliveres J, Sánchez A, Balaguer J, Estruch M, Sánchez J, Solaz C. Efectos de la presencia paterna em quirófano sobre la calidad de la inducción anestésica y agitación postoperatoria em ninõs. Rev. Esp. Anestesiol Reanim. 2011;58(8):472-6. http://dx.doi. org/10.1016/S0034-9356(11)70121-9

7. LaRosa-Nash PA, Murphy JM, Wade LA, Clasby LL. Implementing a parent-present induction program. AORN J. 1995;61(3):526-30. http://dx.doi.org/10.1016/S0001-2092(06)63742-3
8. Doroshow ML, London DL. Surgery and children: a colorful way to introduce children to surgery. AORN J. 1988;47(3):696-700. http://dx.doi.org/10.1016/S0001-2092(07)66522-3

9. Kain ZN, Caldwell-Andrews AA, Mayes LC, Wang SM, Krivutza DM, LoDolce ME. Parental presence during induction of anesthesia: physiological effects on parents. Anesthesiology. 2003;98(1):58-64. PMid:12502980. http://dx.doi. org/10.1097/00000542-200301000-00013

10. Braude N, Ridley SA, Sumner E. Parents and paediatric anesthesia: a prospective survey of parental attitudes to their presence at induction. Ann R Coll Surg Engl. 1990;72(1):41-4. PMid:2301901 PMCid:PMC2499078.

11. Berghmans J, Weber F, Van Akoleyen C, Utens E, Adriaenssens $\mathrm{P}$, Klein J, et al. Audiovisual AID viewing immediately before pediatric induction moderates the accompanying parents' anxiety. Paediatr Anaesth. 2012;22(4):386-92. PMid:22176212. http:// dx.doi.org/10.1111/j.1460-9592.2011.03767.x

12. Himes MK, Munyer K, Henly SJ. Parental presence during pediatric anesthetic inductions. AANA J. 2003;71(4):293-8. PMid:13677225.

13. Chorney JM, Torrey C, Blount R, McLaren CE, Chen WP, Kain ZN. Healthcareprovider and parent behavior and children's coping and distress at anesthesia induction. Anesthesiology. 2009;111(6):12906. PMid:19934874 PMCid:PMC2790460. http://dx.doi. org/10.1097/ALN.0b013e3181c14be5 